\title{
REATIVIDADE DE UMA ESCÓRIA DE SIDERURGIA EM UM LATOSSOLO VERMELHO DISTRÓFICO(1)
}

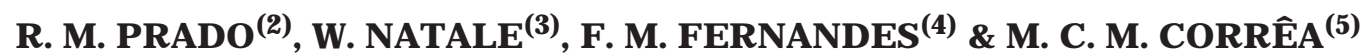

\begin{abstract}
RESUMO
O presente trabalho objetivou estudar a reatividade de uma escória de siderurgia de aciaria, em diferentes frações granulométricas, aplicada em uma amostra de um Latossolo Vermel ho distrófico, ácido, em condições de laboratório. Utilizou-se um fatorial $4 \times 3+2$ com quatro repetições, sendo quatro granulometrias (material retido entre as peneiras AB NT 5-10; 10-20; 20-50 e <50), três doses de escória, correspondentes a 0,00, 5,04 e 10,08 t ha-1 , ou seja, 0,00, 1,01 e 2,02 g por copo com $0,40 \mathrm{dm}^{3}$ de solo e duas testemunhas (escória e calcário dolomítico, na dose correspondente a $V=70 \%$, ou seja, 1,01 e $0,60 \mathrm{~g}$ por copo, respectivamente). Para definir as doses, adotou-se o método da saturação por bases, considerando-se o valor do PRNT da escória e do calcário, obtidos na granulometria correspondente. $O$ solo foi mantido na capacidade de campo e incubado durante os períodos de três, seis e nove meses. As frações granulométricas da escória influiram diferentemente na acidez do solo. A fração retida entre as peneiras AB NT 5-10 mostrou-se ineficiente, enquanto a fração que passa pela peneira ABNT 50 foi a que conferiu o mai or efeito na neutralização da acidez. A reatividade das partículas da escória retidas nas peneiras intermediárias, ABNT 10-20 e 20-50, foi proporcional aos valores vigentes na legislação brasileira para calcários. Portanto, a taxa de reatividade obtida para a escória foi de: ABNT no 5-10 = 0\%; 10-20 = 22 \%; 20-50 =58 \% e < $50=100 \%$.
\end{abstract}

Termos de indexação: calagem, reação do solo, resíduo siderúrgico, granulometria, legislação de corretivos.

\footnotetext{
(1) Recebido para publicação em outubro de 2002 e aprovado em setembro de 2003.

(2) Professor Substituto do Departamento de Sol os e Adubos, Faculdade de Ciências Agrárias e Veterinárias, Universidade Estadual Paulista - UNESP. Via de Acesso Prof. Paulo Donato Castellane, s/n., CEP 14870-000 J aboticabal (SP). E-mail: rmprado@fcav.unesp.br

(3) Professor Adjunto do Departamento de Solos e Adubos, Faculdade de Ciências Agrárias e Veterinárias, UNESP. Bolsista do CNPq. E-mail: natale@fcav.unesp.br

(4) Professor Adjunto do Departamento de Fitossanidade, Engenharia Rural e Solos, Faculdade de Engenharia de IIha Solteira, UNESP. Caixa Postal 31, CEP 15385-000 IIha Solteira (SP). E-mail: maximino@agr.feis.unesp.br

${ }^{(5)}$ Doutor em Produção Vegetal, Departamento de Solos e Adubos, Faculdade de Ciências Agrárias e Veterinárias, UNESP.
} 


\title{
SUMMARY: REACTIVITY OF A SLAG IN A DISTROFIC RED LATOSOL
}

\begin{abstract}
Thepresent study investigated thereactivity of a slag from sted works in different particle sizefractions, applied on an acid dystrophic Red Latosol, under laboratory conditions, in a $4 \times 3+2$ factorial scheme in four replications. Four particlesizes (material retained in the ABNT 5-10; 10-20; 20-50, and <50 sieves), three doses of slag (0.00, 5.04, and $10.08 \mathrm{t} \mathrm{ha}^{-1}$, corresponding to $0.00,1.01$, and $2.02 \mathrm{~g}$ in $0.40 \mathrm{dm}^{3}$ of soil per cup) and two control treatments (slag and dolomitic limestone in the corresponding dose to base saturation (V) $=70 \%$, or either, 1.01 and $0.61 \mathrm{~g}$ per cup, respectively). The base saturation method was used for the definition of the doses, considering the $\mathrm{CaCO}_{3}$ equival ent value of slag and limestone, for thecorresponding particlesizefractions. Thesoil humi dity was maintained at fiel d capacity and incubated for three, six, and nine months. Grain size fractions of the slag affected differently theacidity of thesoil. Thefraction retai ned between theABNT 5-10 sieves proved to be inefficient, while the fraction that passed through ABNT $<50$ was the one with the greatest effect on acidity neutralization. The reactivity of retained slag particles in the intermediate sieves (ABNT 10-20 and 20-50 sieves) was proportional to the effectivevalues of the Brazilian legislation for lime. Ther efore, the reactivity rate obtained for steel work slag was: ABNT no 5-10 $=0 \%$; $10-20=22 \% ; 20-50=58 \%$ e $<50=100 \%$.
\end{abstract}

Index terms: liming, soil reaction, steel work residue, particlesize, fertilizer legislation.

\section{INTRODUÇÃO}

É conhecido o potencial de usoagrícola da escória de siderurgia como alternativa ao tradicional calcário, com a vantagem que seu uso diminui o impacto ambiental em torno das indústrias produtoras de ferro e aço.

Atual mente, a escória desi der urgia éclassificada como corretivo de acidez do solo, aplicando-lhe a mesma legislação do cal cário para sua comercialização. Assim, o material corretivo mais utilizado no Brasil é o calcário, assim como o mais pesquisado, visto que são consumidas cerca de 19,812 milhões de toneladas anual mente, considerando o ano de 2000 (Abracal, 2001, citado por POTAFOS, 2003). De acordo com a legislação brasileira de corretivos de acidez do solo (Brasil, 1983), o calcário deve apresentar características mínimas para ser comercializado no tocanteao poder de neutralização e reatividade, ao passo que, para a escória de siderurgia, a exigência mínima está restrita apenas ao poder de neutralização.

Para que o material atue como corretivo de acidez do solo com alta eficiência, não é suficiente apenas que apresente alto poder de neutralização, mas que o tempo para que haja correção da acidez seja satisfatoriamente rápido. Assim sendo, diz-se que este fenômeno está relacionado, especialmente, com o grau de moagem do material, ou seja, com sua granulometria, embora a natureza química também possa influenciar.

Pela prática agrícola, convencionou-se que a reatividade (RE) relativa a uma fração granulométrica é a sua capacidade de ação na neutralização da acidez do solo num período de três meses. Segundo a legislação dos calcários, para a fração superior a $2 \mathrm{~mm}$ (peneira ABNT № 10) e inferior a $0,30 \mathrm{~mm}$ (peneira ABNT № 50) foram atribuídos os val ores 0 e $100 \%$ de reatividade, respectivamente, e, a partir destas, foram atribuídas as eficiências correspondentes às granulometrias intermediárias entre $2 \mathrm{e}$ $0,30 \mathrm{~mm}$. No cálculo da reatividade dos calcários, convencionou-se que a fração das partículas retidas entre as peneiras ABNT 10 e 20 têm $20 \%$ de RE e aquelas partículas retidas entre as peneiras ABNT 20 e 50 têm RE de $60 \%$, conforme indica a legislação (Brasil, 1986).

Entretanto, quando estes resultados da taxa de RE estabelecidos pela legislação brasileira são extrapolados para a escória, podem-se obter erros, visto que, mesmo para os próprios calcários, essas taxas não encontraram respaldo na literatura (Bellingieri et al.,1988; N atale \& Coutinho, 1994).

Comosão materiais distintos, pode-seadmitir que as taxas de RE utilizadas para o cal cário talvez não expressem a mesma realidade no caso da escória, visto que este produto apresenta constituição química efísica complexa e distinta do cal cário. Esta diferença aparece desde a composição da escória (silicatos de cálcioe magnésio associados a compostos deFe, $\mathrm{Al}$ e Mn) e durante a fase de produção destes resíduos (Prado et al., 2001). Esses autores complementam que, no processo industrial, o resfriamento da escória, no momento de saída do forno da siderúrgica, pode afetar sua qualidade; assim, se a escória não receber um resfriamente 
rápido ("quenching"), com jatos d'água, ocorrerá maior recristalização dos seus constituintes, o que poderá reduzir sua solubilidade.

Nos poucos trabalhos que trataram da RE da escória, empregaram-se materiais com granulometrias muito finas (peneiras ABNT $\mathrm{n}->10 ; 20-40 ; 40-$ 70; 140-200 e <200 (Camargo, 1972); ABNT >50; 50-100 e < 50) (Louzada, 1987); ABNT 20-50; 50-100; 100-150 e <150 (Bahia, 1989); ABNT 50-60 e 100140 (Piau, 1991); ABNT 20 até < 270 (F ortes, 1993). Assim, não existem estudos para a escória de siderurgia que estabeleçam a RE para as frações granulométricas constante na legislação brasileira (ABNT >10; 10-20; 20-50 e <50), de acordo com Prado et al. (2001). O conhecimento sobre a granulometria, comum no caso dos cal cários, visa a adequar a qualidade técnica do material corretivo e o seu custo de produção, de forma que os extremos das frações sejam adequadamente definidos; partículas finas (ABNT <50), além de apresentarem alto custo no processo de moagem, têm baixo efeito residual, ao passo que partículas grosseiras (ABNT > 10) têm efeito desprezível nas mudanças da reação do solo, mesmo ao longo do tempo.

Diante disso, o presente trabalho objetivou estudar a reatividade da escória de siderurgia de aciaria em diferentes frações granulométricas aplicada em amostras de um Latossolo Vermelho distrófico, ácido, em condições de laboratório.

\section{MATERIAL E MÉTODOS}

Foram utilizadas amostras de um Latossolo Vermelho distrófico, da Estação Experimental de Citricultura de Bebedouro, São Paulo. Essas amostras foram coletadas da camada de $40-60 \mathrm{~cm}$ de profundidade, em um perfil de $5 \mathrm{~m}$, homogeneizadas, secas ao ar e passadas em peneiras com malha de
$2 \mathrm{~mm}$ de abertura. Realizou-se a análise química, conforme método descrito por Raij et al. (2001), que revelou as seguintes características: $\mathrm{pH}\left(\mathrm{CaCl}_{2}\right)=4,7$; $\mathrm{MO}=3 \mathrm{~g} \mathrm{~kg}^{-1} ; \mathrm{P}$ (resina) $=4 \mathrm{mg} \mathrm{dm}^{-3} ; \mathrm{K}^{+}=0,3 ; \mathrm{Ca}^{2+}=8$; $\mathrm{Mg}^{2+}=4 \mathrm{eH}+\mathrm{Al}=38 \mathrm{mmol}_{\mathrm{c}} \mathrm{dm}^{-3} ; \mathrm{SB}$ (soma de bases) $=12,3$; CTC (capacidade de troca catiônica) = $50,3 \mathrm{mmol}_{\mathrm{c}} \mathrm{dm}^{-3} \mathrm{eV}=24 \%$.

Utilizou-se uma escória siderúrgica de aciaria, com diferentes granulometrias, e um calcário dolomítico, com sua granulometria original (Quadro 1). Observa-se que a granulometria grosseira (ABNT no 5-10) da escória apresentou PN baixo, mostrando que os extratores utilizados solubilizaram apenas a camada superficial das partículas. Além disso, nota-se que o PN calculado foi maior que o determinado. Segundo Alcarde \& Rodella (1996), este fato é explicado por ser o PN calculado com base em teores obtidos por um processo mais energético (maior concentração de áci do etempo de agitação) e, ainda, por este método admitir quetodo Ca e Mg determinado estaria ligado a uma base química neutralizante de forma que também considera aquelas bases químicas inexpressivas na neutralização da acidez, como sulfato e fosfato. Os autores consideram, ainda, que o PN determinado fundamenta-se em fazer uma amostra de corretivo exercer toda sua capacidade deneutralização sobre uma quantidade conhecida e em excesso de ácido clorídrico.

Para avaliação do PN dos materiais corretivos, utilizou-se o método oficial brasileiro definido para os cal cários (Brasil, 1983). A reatividade da escória (RE) e do cal cário dol omítico foi de 67,69 \% (ABNT no $10=5,21 ; 10-20=17,78 ; 20-50=32,33$ e $<50=$ $44,74 \%$ ) e $81,70 \%$ (ABNT oo $10=1,96 ; 10-20=9,54$; $20-50=21,74$ e $<50=66,76 \%$ ), respectivamente. O PRNT ((PN x RE)/100), da escória e do calcário, foi de 45,88 e $79,66 \%$, respectivamente.

Utilizou-se um fatorial $4 \times 3+2$, com quatro repetições, sendo quatro granulometrias (ABNT 5-10;

Quadro 1. Características químicas dos materiais corretivos utilizados no experimento

\begin{tabular}{|c|c|c|c|c|}
\hline \multirow{2}{*}{ Material corretivo (frações) } & \multirow{2}{*}{$\mathrm{CaO}(1)$} & \multirow{2}{*}{ MgO(1) } & \multicolumn{2}{|c|}{$\% \mathrm{ECaCO}_{3}^{(2)}$} \\
\hline & & & Calculado(1) & Determinado(3) \\
\hline & & 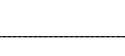 & - & - \\
\hline \multirow[t]{2}{*}{ Escória de aciaria } & 29,31 & 6,18 & 67,78 & 60,00 \\
\hline & \multicolumn{4}{|c|}{ Diferentes granulometrias da escória de aciaria } \\
\hline ABNT 5-10 & 18,76 & 5,04 & 46,07 & 39,00 \\
\hline ABNT $10-20$ & 27,63 & 5,98 & 64,28 & 47,75 \\
\hline ABNT $20-50$ & 28,37 & 6,38 & 66,61 & 60,25 \\
\hline ABNT $<50$ & 26,41 & 6,52 & 63,44 & 62,25 \\
\hline Calcário dolomítico & 26,60 & 20,08 & 97,48 & 88,17 \\
\hline
\end{tabular}


10-20; 20-50 e <50), três doses de escória correspondentes a 0,00; 5,04 e 10,08 t ha-1, ou seja, 0,00; 1,01, e 2,02 g por copo com 0,40 dm³ de solo) e duas testemunhas (escória e cal cário dolomítico na dose correspondente ao $\mathrm{V}=70 \%$, ou seja, 1,01 e $0,60 \mathrm{~g}$ por copo com $0,40 \mathrm{dm}^{3}$ de solo, respectivamente). As diferenças granulométricas da escória foram obti das por peneiramento; entretanto, nas frações mais grosseiras (ABNT 5-10; 10-20 e 2050), procurou-se retirar a "poeira", ou seja, frações muito finas da escória, evitando-se eventual contaminação.

Para definir as doses, adotou-se o método da saturação por bases (Raij et al., 1996), considerandose o valor do PRNT da escória e do calcário dolomítico. Cabe salientar que este procedimento ocorreu para comparar as testemunhas (escória e calcário), apenas como avaliação preliminar e certificar as diferenças entre os materiais na reação do solo, partindo das mesmas taxas de reatividade adotadas pela legislação de calcário. Para avaliar os fatores granulometria e doses de escória, objeto principal do trabalho, utilizou-se a dose de 5,04 t ha-1, al ém do zero e o dobro disso, apenas para possibilitar doses crescentes, sem a pretensão de atingir níveis de correção predeterminados, uma vez que determinar as taxas de reatividade da escória era o objeto principal deste estudo. Procedimentos semel hantes foram utilizados por Natale\& Coutinho (1994), quando avaliaram os fatores: granulometria e doses de calcário, em um trabalho de campo.

Os materiais corretivos, nas diferentes doses e granulometrias, foram homogeneizados com amostras do solo e acondicionados em copos de plástico com 0,40 $\mathrm{dm}^{3}$ de solo, compondo a unidade experimental.

A umidade do sol o foi mantida na capacidade de campo e o sol o incubado durante os períodos de três, seis e nove meses. Após cada período de incubação o solo de cada tratamento foi seco, passado em peneira de $2 \mathrm{~mm}$ eamostrado para anál ises químicas para fins defertilidade $\left(\mathrm{pH}, \mathrm{H}+\mathrm{Al}, \mathrm{K}^{+}, \mathrm{Ca}^{2+} \mathrm{eMg}^{2+}\right)$, conforme método descrito por Raij et al . (2001), bem como foram calculadas a soma e a saturação por bases.

Para o cál culo do índice médio de eficiência equivalente, utilizou-se, como padrão, a fração $A B N T<50$, em relação às diferentes frações pesquisadas, conforme indicações de $\mathrm{N}$ atale \& Coutinho (1994), obtidas pelo quociente entre os coeficientes angulares (b) das curvas de saturação por bases em função de doses el evado ao quadrado e, finalmente, multiplicando-se por 100 para a expressão dos resultados em percentagem, como se segue:

$$
\begin{gathered}
\text { Eficiência (ABNT <50) }=[\text { b (frações ABNT } \\
5-10 \text { ou } 10-20 \text { ou 20-50)/b ABNT <50 }]^{2} \times 100
\end{gathered}
$$

Os resultados referentes às frações granulométricas foram comparados pelo teste $t$, segundo descrição deVieira (1999), ea escol ha do model o final foi feita segundo indicações de Alvarez V. (1985).

É oportuno salientar quea escol ha como padrão, da fração ABNT <50 ocorreu pelo fato de ser essa fração utilizada para o calcário com RE $=100 \%$, conforme a legislação. A escória apresenta-se mais abrasiva que o cal cário (Prado et al., 2001), de forma que os moinhos brasileiros não teriam a capacidade técnica e econômica para a moagem deste resíduo em granulometria muito fina, além da comumente utilizada para os calcários.

\section{RESULTADOS E DISCUSSÃO}

Houve diferença significativa entre os tratamentos do fatorial (granulometria e doses) e as testemunhas (escória e calcário dolomítico) durante três, seis e nove meses de incubação (Quadro 2). I sto indica que existe variação nas alterações das características químicas do solo, provocadas por variação na granulometria do corretivo. Este fato foi verificado por Kurihara et al. (1999) em cal cários de diferentes origens. Assim, notou-se que os fatores: granul ometrias, doses esuas interações, foram significativos nas alterações do valor $\mathrm{pH}, \mathrm{H}+\mathrm{Al}, \mathrm{Ca}^{2+}, \mathrm{Mg}^{2+}$, soma de bases e saturação por bases do solo. A interação significativa ocorreu, tendo em vista que a el evação dos valores do $\mathrm{pH}, \mathrm{Ca}^{2+}, \mathrm{Mg}^{2+}$, soma de bases e da saturação por bases se deu com o aumento das doses de escória e com a diminuição da granulometria (ocorrendo o inverso para o $\mathrm{H}+\mathrm{Al}$ ), exceto para a mais grosseira (ABNT 5-10), que se apresentou indiferente à aplicação da escória.

Além disso, houve diferença entre as testemunhas, ou seja, o cal cário dolomítico e a escória de aciaria, exceto para $\mathrm{H}+\mathrm{Al} \mathrm{e} \mathrm{Ca}^{2+}$ aos três e nove meses de incubação e o $\mathrm{Ca}^{2+}$ aos seis meses de incubação (Quadro 2).

As diferenças significativas verificadas entre as testemunhas nas alterações químicas do solo indicam superioridade do cal cário na neutralização da acidez do solo, exceto as variáveis $\mathrm{H}+\mathrm{Al}, \mathrm{Ca}^{2+} \mathrm{e}$ $\mathrm{V}$, aos três meses, eo $\mathrm{Ca}^{2+}, \mathrm{Mg}^{2+} \mathrm{eSB}$, aos seis meses, e o $\mathrm{pH}, \mathrm{H}+\mathrm{Al}, \mathrm{Ca}^{2+}, \mathrm{Mg}^{2+}, \mathrm{SB}$ e $\mathrm{V}$, aos nove meses de incubação (Quadro 2). I sto evidencia o comportamento distinto dos materiais corretivos na eficiência da neutralização da acidez do solo, tendo em vista as diferenças de natureza química dos materiais (silicato ecarbonato) esua granulometria.

Para os resultados das características químicas do solo, dependendo das frações granulométricas da escória de siderurgia, dentro de cada período de incubação (Figura 1), verificou-se el evação dos 


\section{Quadro 2. Características químicas do solo, de acordo com a aplicação de escória de aciaria e calcário dolomítico, em doses equivalentes ${ }^{(1)}$}

\begin{tabular}{|c|c|c|c|c|c|c|}
\hline Material corretivo & $\mathrm{pH}\left(\mathrm{CaCl}_{2}\right)$ & $\mathbf{H}+\mathbf{A l}$ & $\mathrm{Ca}^{2+}$ & $\mathbf{M g}^{2+}$ & SB & $\mathbf{V}$ \\
\hline & & \multicolumn{4}{|c|}{$-\mathrm{mmol}_{\mathrm{c}} \mathrm{dm}^{-3}$} & \multirow[t]{2}{*}{$\%$} \\
\hline & & & Três me & cubação & & \\
\hline \multirow[t]{2}{*}{$\begin{array}{l}\text { Escória de aciaria } \\
\text { Calcário dolomítico }\end{array}$} & $\begin{array}{l}6,6 \mathrm{~b} \\
7,0 \mathrm{a}\end{array}$ & $\begin{array}{l}11 a \\
10 a\end{array}$ & $\begin{array}{l}18 a \\
18 a\end{array}$ & $\begin{array}{r}6 \mathrm{~b} \\
10 \mathrm{a}\end{array}$ & $\begin{array}{l}25,0 \mathrm{~b} \\
28,5 \mathrm{a}\end{array}$ & $\begin{array}{l}69 a \\
74 a\end{array}$ \\
\hline & \multicolumn{6}{|c|}{ Seis meses de incubação } \\
\hline \multirow[t]{2}{*}{$\begin{array}{l}\text { Escória de aciaria } \\
\text { Calcário dolomítico }\end{array}$} & $\begin{array}{l}6,9 \mathrm{~b} \\
7,1 \mathrm{a}\end{array}$ & $\begin{array}{r}10 \mathrm{a} \\
8 \mathrm{~b}\end{array}$ & $\begin{array}{l}15 a \\
15 a\end{array}$ & $\begin{array}{l}5 a \\
5 a\end{array}$ & $\begin{array}{l}20,5 a \\
20,4 a\end{array}$ & $\begin{array}{l}68 b \\
72 a\end{array}$ \\
\hline & \multicolumn{6}{|c|}{ Nove meses de incubação } \\
\hline $\begin{array}{l}\text { Escória de aciaria } \\
\text { Cal cário dolomítico }\end{array}$ & $\begin{array}{l}6,7 a \\
6,8 a\end{array}$ & $\begin{array}{c}11 a \\
9 a\end{array}$ & $\begin{array}{l}19 a \\
17 a\end{array}$ & $\begin{array}{l}9 \mathrm{a} \\
7 \mathrm{~b}\end{array}$ & $\begin{array}{l}28,0 a \\
25,0 a\end{array}$ & $\begin{array}{l}74 a \\
75 a\end{array}$ \\
\hline
\end{tabular}

(1) Doses de escória de aciaria e calcário dolomítico, correspondendo a 5,04 e 2,91 t ha-1, respectivamente.

Médias seguidas de mesma letra, na coluna, dentro de cada período de incubação, não diferenciam entre si pelo teste Tukey a $5 \%$.

valores $\mathrm{pH}$, bem como uma redução do $\mathrm{H}+\mathrm{Al}$, à medida que a fração granulométrica da escória diminui, como esperado. Em relação ao $\mathrm{Ca}^{2+} \mathrm{eMg}^{2+}$, as frações mais finas apresentaram os maiores valores nas alterações destes nutrientes no solo, enquanto a fração mais grosseira (peneira ABNT no 5-10) mostrou-se pouco efetiva. As frações mais grosseiras (peneira ABNT no 5-10 e 10-20) foram semelhantes quanto à concentração de $\mathrm{Ca}^{2+}$ aos três meses de incubação e de $\mathrm{Mg}^{2+}$ aos seis e nove meses de incubação. As frações mais finas (peneira ABNT $\mathrm{n} \circ<50$ ) e peneira ABNT $\mathrm{n}-20-50$ promoveram sempre as maiores concentrações de $\mathrm{Ca}^{2+} \mathrm{eM} \mathrm{g}^{2+}$ no sol o em todos os tempos de incubação.

Verificou-se, que, já aos três meses de incubação, o efeito da granul ometria na concentração de bases no solo foi significativo (Figura 1). Alguns autores não verificaram efeito da granulometria da escória na concentração de bases do solo. L Louzada (1987) trabalhou com escória de granulometria ABNT > 50 até $<100$, não verificando aumento da concentração de $\mathrm{Ca}^{2+}$ no solo, durante 30 dias de incubação. Piau (1995) comparou a escória de granulometria grosseira (36 \% passando pela peneira ABNT <50) e fina $(<50$ e $>60)$ e não observou efeito na concentração de $\mathrm{Ca}^{2+}$ e $\mathrm{Mg}^{2+}$ durante 90 dias de incubação. Todavia, Piau (1991), trabalhando com granulometrias muito finas de escória desiderurgia, observou efeito significativo dessa característica na concentração de bases no solo, quando comparou a granulometria da escória da peneira ABNT 50-60 com a 100-140, no período de 30 até 90 dias de incubação. Nota-se que os trabal hos da literatura apresentam diversas granulometrias, as quais, muitas vezes, são mais finas que o padrão definido pela legislação (peneira ABNT <50).

As alterações de $\mathrm{Ca}^{2+} \mathrm{e} \mathrm{M} \mathrm{g}^{2+}$ também refletiram, de forma direta, na soma de bases e na saturação por bases do solo, observando-se, nesteúltimo, maior discriminação da eficiência das frações granulométricas (Figura 1). Natale\& Coutinho(1994) constataram, também, a superioridade da saturação por bases para discriminar a eficiência das frações granulométricas do cal cário. Outros autores utilizaram o valor depH para avaliar a eficiência das frações granulomé tricas de calcários (Bellingieri, 1983) e escória (Camargo, 1972). Empregar a saturação por bases (V) para avaliar a eficiência de corretivos em diferentes frações granulométricas tem, ainda, uma vantagem prática adicional, visto que um dos métodos de recomendação de calagem baseia-se no valor de $\mathrm{V}$.

É importante destacar, também, que, dentro de cada tempo de incubação, a fração mais fina da escória (peneira $A B N T<50$ ) foi sempre superior à da peneira ABNT 20-50, indicando quea fração mais fina não per deu sua ação neutralizante com o tempo, a exemplo da saturação por bases, quando comparadas as frações que passaram pelas demais peneiras, mantendo o efeito benéfico por até nove meses de incubação (Figura 1). Por outro lado, Kurihara et al. (1999) notaram perda considerável da ação neutralizante, especial mente da fração fina (ABNT 50-70) de calcários sedimentares após 233 dias de incubação. Assim, pode-se inferir que a escória apresenta um efeito residual maior que o calcário, visto quea fração fina destematerial émais susceptível à perda de ação com o tempo.

Avaliando o efeito das frações granulométricas de acordo com as doses, verificou-se que as maiores alterações nas características de acidez do sol o foram: aumento do $\mathrm{pH}$ e redução da concentração de $\mathrm{H}+\mathrm{Al}$, incremento na concentração de $\mathrm{Ca}^{2+} \mathrm{e} \mathrm{Mg}^{2+} \mathrm{e}$ el evação da soma de bases e da saturação por bases (F igura 1), que ocorreram com a el evação das doses aplicadas do material, duranteo períodoexperimental. Isto é explicado pela dependência da solubilização 
da escória de acordo com o maior fracionamento das partículas, possibilitando maior contatocorretivo-solo.

Cabe salientar que a fração mais grosseira (ABNT 5-10) da escória não influiu significativamente nas variáveis em estudo aos três meses deincubação; todavia, aos seis e nove meses houve resposta significativa para a saturação por bases, embora tenha sido uma alteração pequena. Este fato mostra que a fração mais grosseira da escória é ineficiente na neutral ização da acidez do solo, mesmo em doses el evadas e por um período de incubação de até nove meses. Assim, nota-se que a granulometria fina provocou maiores alterações na neutralização da acidez do solo. I sto está relacionado com o aumento da superfície específica das partículas, favorecendo as reações desolubilização da escória eneutral ização da acidez do solo. Resultados semelhantes foram obtidos por Bellingieri (1983) e Plese et al. (2000), em condições de laboratório, utilizando cal cários, e por Piau (1991), empregando escória de siderurgia, tendoa granulometria mais fina conferido os maiores aumentos de $\mathrm{pH}$ ao solo. Desse modo, quanto mais finas as partículas, mais rápida sua ação na correção da acidez do solo, como também observado por Swartzendruber \& Barber (1965).

Conforme comentado anteriormente, a saturação por bases discriminou melhor os efeitos das fraçốes granulométricas no solo e, assim, optou-se por trabalhar com as equações de regressão obtidas (Figura 2), calculando-se a eficiência da escória, tomando-sea fração mais fina (peneira no $\mathrm{ABNT}<50$ ) como padrão eatribuindo-lheeficiência igual a $100 \%$ (Quadro 3). O cálculo do índice médio de eficiência equivalente à fração $A B N T<50$ representa uma análise comparativa das curvas, sustentada pelo teste estatístico de paralelismo entre a peneira padrão e as demais em estudo, conforme o procedimento comentado anteriormente.
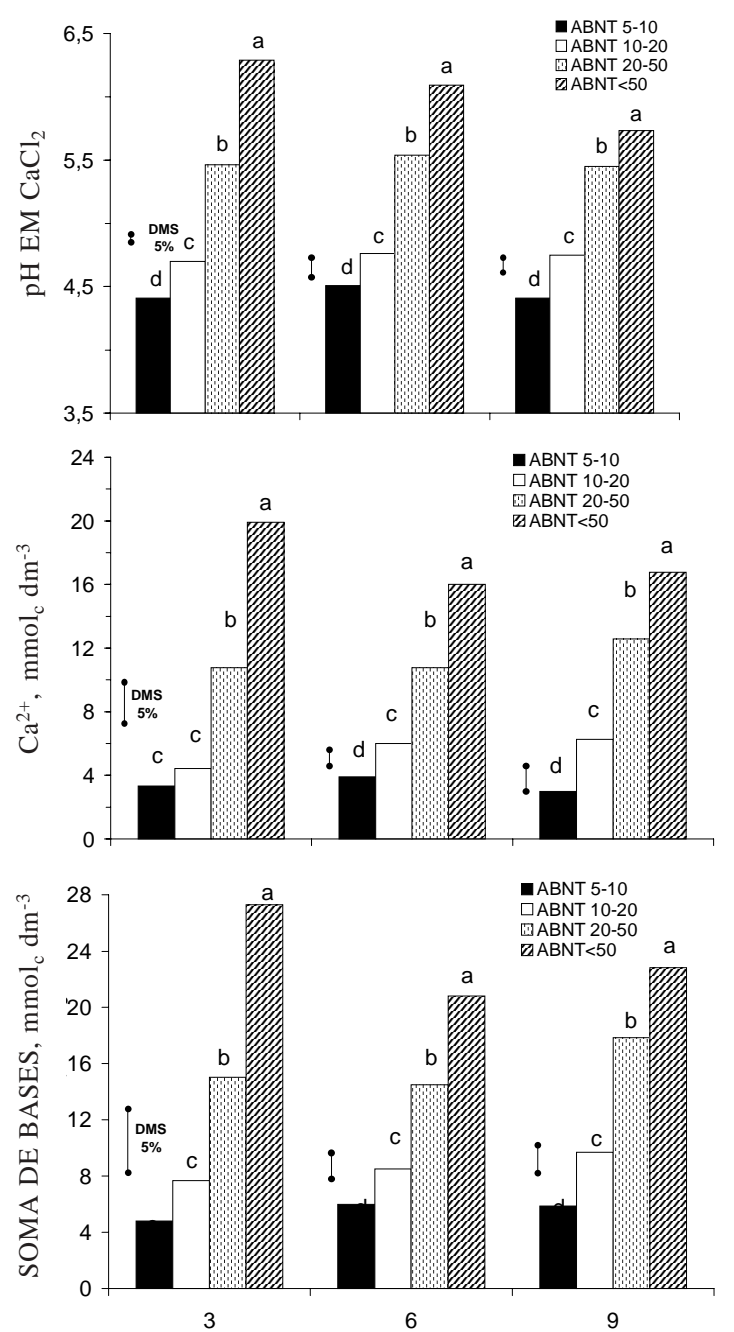
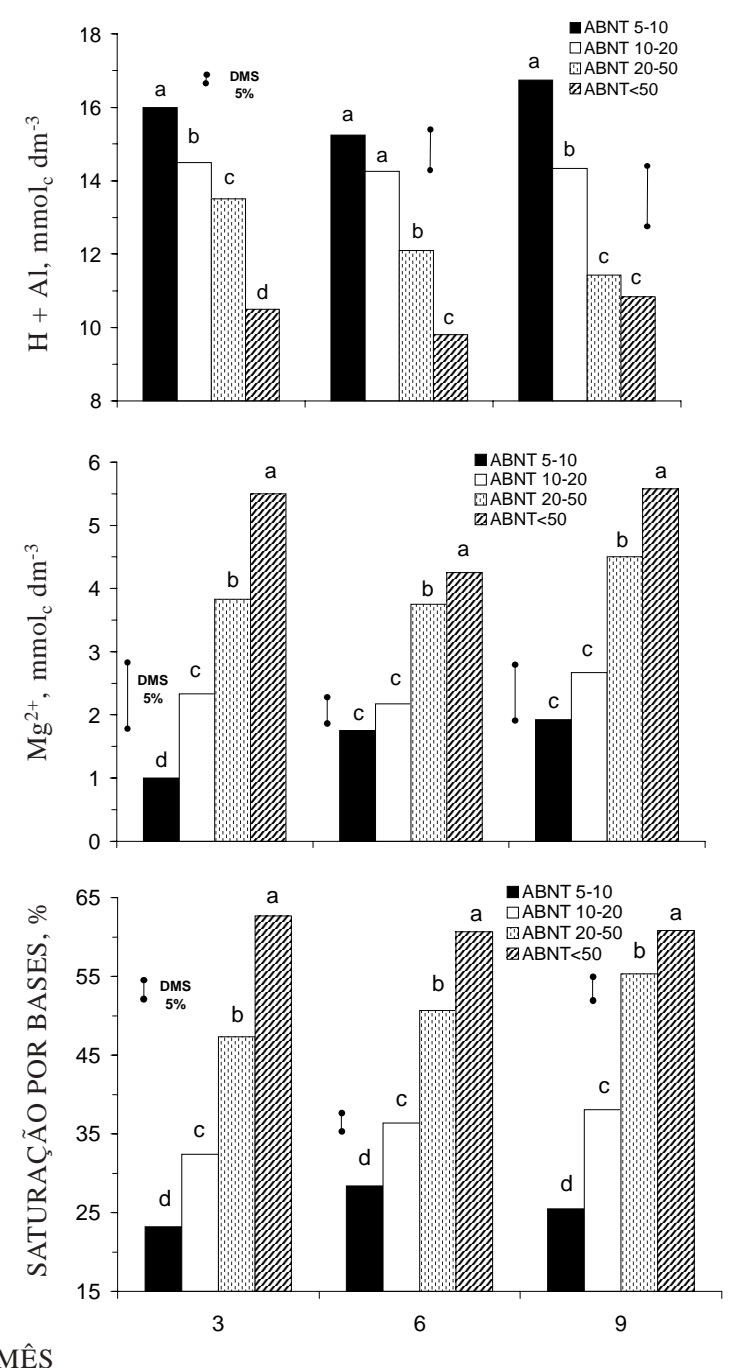

Miss

Figura 1. Frações granulométricas da escória de siderurgia de aciaria no valor pH, concentrações de $\mathrm{H}+\mathrm{Al}, \mathrm{Ca}^{2+}, \mathrm{Mg}^{2+}$, soma de bases e na saturação por bases de um Latossolo Vermelho distrófico, após três, seis e nove meses de incubação (média de três doses e quatro repetições). 

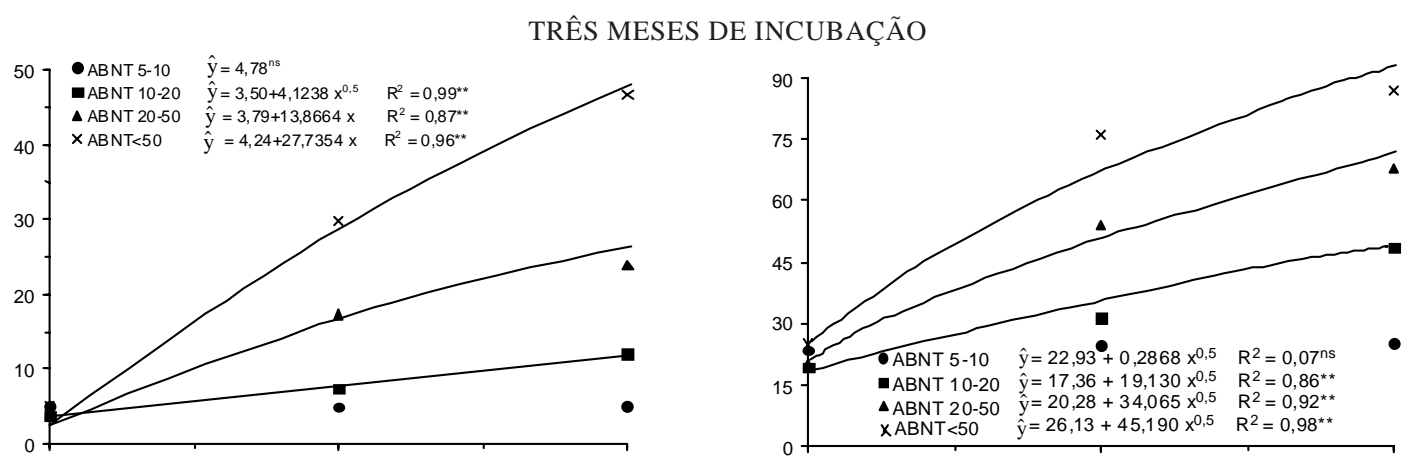

SEIS MESES DE INCUBAÇÃO
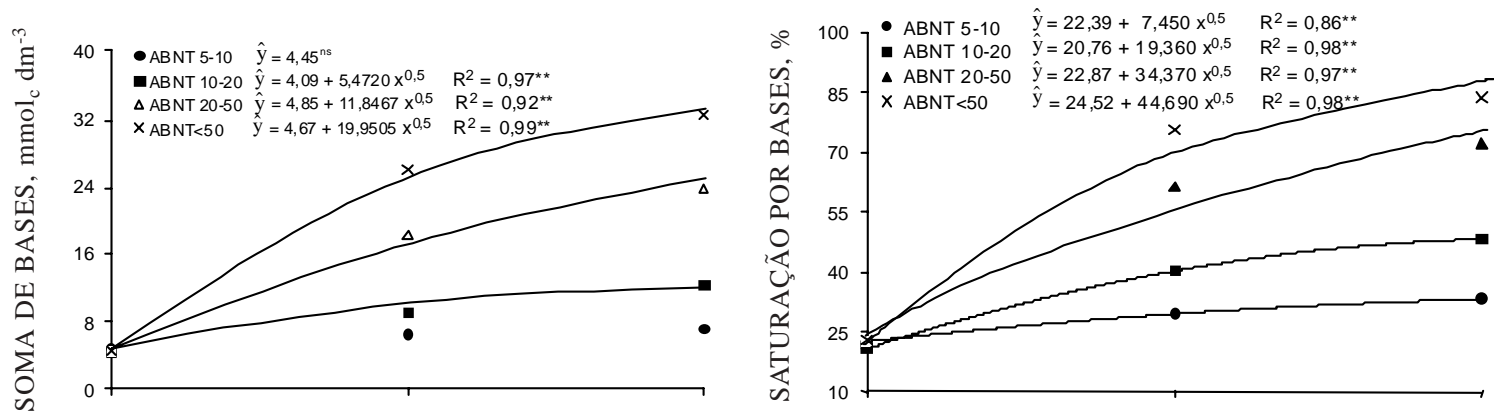

NOVE MESES DE INCUBAÇÃO
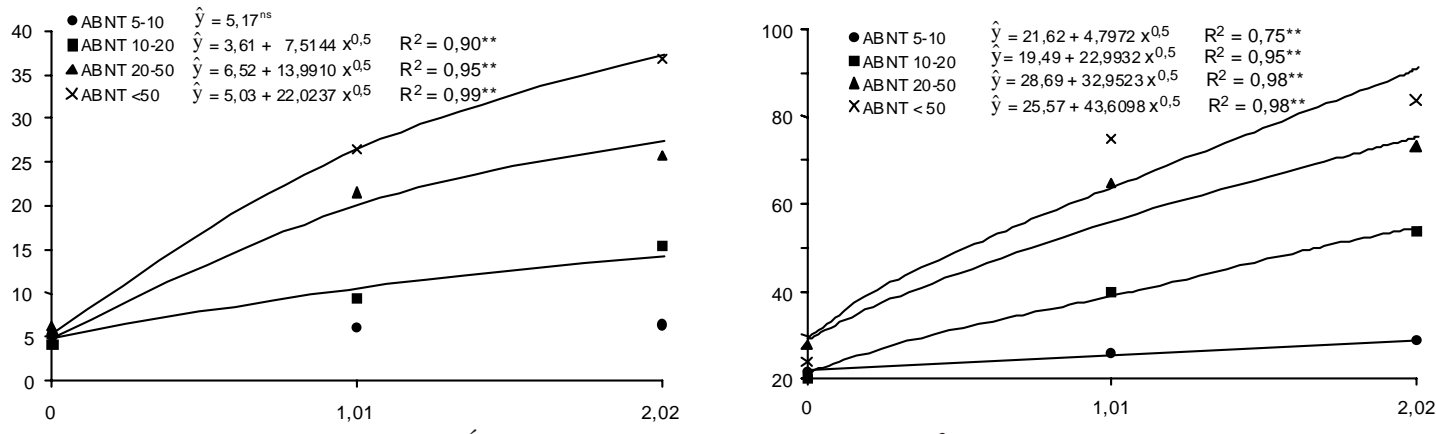

ESCÓRIAAPLICADA, g por copo $\left(0,40 \mathrm{dm}^{3}\right.$ de solo $)$

Figura 2. Frações granulométricas da escória de siderurgia na soma de bases e na saturação por bases de um Latossolo Vermelho distrófico, após três, seis e nove meses de incubação.

Quadro 3. Índice médio de eficiência equivalente à fração da peneira AB NT <50, de acordo com o tempo de incubação

\begin{tabular}{|c|c|c|c|c|c|c|}
\hline \multirow{2}{*}{ Peneira } & \multicolumn{2}{|c|}{ Três meses } & \multicolumn{2}{|c|}{ Seis meses } & \multicolumn{2}{|c|}{ Nove meses } \\
\hline & Índice & $t^{(1)}$ & Índice & $\mathbf{t}$ & Índice & t \\
\hline ABNT 5-10 & $<1$ & $-16,4 * *$ & 3 & $-13,3 * *$ & 1 & $-13,6^{* *}$ \\
\hline ABNT $10-20$ & 18 & $-6,0 * *$ & 19 & $-9,3^{* *}$ & 28 & $-6,0 * *$ \\
\hline ABNT $20-50$ & 57 & $-2,3^{*}$ & 59 & $-3,0 * *$ & 57 & $-3,2 * *$ \\
\hline ABNT $<50$ & 100 & - & 100 & - & 100 & \\
\hline
\end{tabular}

(1) Teste t para paralelismo, entre a reta da peneira ABNT <50 e a respectiva reta. *, ** resultados significativos a 5 e $1 \%$, respectivamente.

Por estes resultados, nota-se que a eficiência da escória aumenta com a diminuição da fração granulométrica, durante o período estudado, atingindo 0-3; 18-28; 57-59 \%, para as frações correspondente às peneiras ABNT 5-10; 10-20 e 2050 , respectivamente, quando comparada com a da 
ABNT $<50$, considerando-se a saturação por bases do sol o (Quadro 3). I sso demonstra quea reatividade da escória, nas diferentes granulometrias, é semelhante à do calcário em condições de laboratório, adotadas pela legislação (Brasil, 1986), sendo maior, quando comparada ao calcário em condições de campo (Natale \& Coutinho, 1994). É oportuno salientar que a divergência entre valores de reatividade do cal cário, observada na literatura, quando se comparam laboratório e campo, requer que para escória desiderurgia esta situação também seja considerada. Assim sendo, é importante pesquisar, em condições de campo, as taxas de reatividade da escória de siderurgia, antes de se adotarem valores definitivos.

Nota-se, ainda, que a escória mantém índices de reatividade praticamente constante com o tempo de incubação, a exemplo da peneira ABNT 20-50 (57 até 59 ), e com moderado aumento na peneira ABNT 10-20 (18 até 28) (Quadro 3). I sto indica que não houve perda de efeito ao longo do tempo de incubação (período de três-nove meses) das diferentes frações granulométricas da escória de siderurgia. I sto pode ser explicado pelo fato de o solo deste experimento não ter sofrido efeito de aci dificação e, ou, remoção de bases, o que provocaria maior solubilização da escória. Kato \& Owa (1996) observaram, em estudo de equilíbrio químico em solução aquosa, que a escória de siderurgia pode sofrer um decréscimo acentuado na sua dissolução, à medida que aumentam o pH ea concentração de Ca na solução do solo. No entanto, é provável que este efeito na solubilização da escória de siderurgia seja mais pronunciado nas fases iniciais da sua incorporaçãoaosoloe, posteriormente, em campo, estes efeitos sejam minimizados pel os fenômenos delixi viação de bases, absorção pelas plantas e pelos processos de reacidificação do solo, a exemplo da causada pela adubação nitrogenada, os quais irão, com o tempo, influenciar as reações de equilíbrio químico e possibilitar maior solubilização da escória de siderurgia.

Cabe salientar, ainda, que a reatividade semel hante dos materiais (cal cário e escória) e o fato de o cal cário ter promovido mai or neutralização da acidez do solo, especialmente aos seis meses de incubação para variável saturação por bases (Quadro 2), revelem que esta diferença pode ter ocorrido por fatores químicos (Equival ente em $\left.\mathrm{CaCO}_{3}-\% \mathrm{ECaCO}_{3}\right)$, visto que a reatividade foi semelhante (Quadro 3), uma vez que existem diferenças em todas as granulometrias da escória entre $\% \mathrm{ECaCO}_{3}$, calculado e determinado (Quadro 1). Prado \& Fernandes (2000), em estudos com escória e calcário em condições de casa de vegetação, também ressaltaram a necessidade de novos estudos de métodos de determinação do PN para a escória de siderurgia.

\section{CONCLUSÕES}

1. A escória de siderurgia, em suas diferentes frações granulométricas, influenciaram diferentemente a acidez do solo.

2. A fração retida entre as peneiras ABNT 5-10 mostrou-seineficiente, enquanto a fração que passa pela peneira ABNT 50 foi a que conferiu o maior efeito na neutralização da acidez. A reatividade das partículas da escória de siderurgia retidas nas peneiras intermediárias, peneiras ABNT 10-20 e2050 , foi proporcional aos val ores vigentes na legislação brasileira para calcários. Portanto, a taxa de reatividade obtida para a escória de aciaria foi de: ABNT no 5-10 = 0\%; $10-20=22 \% ; 20-50=58 \%$ e $<50=100 \%$.

\section{LITERATURA CITADA}

ALCARDE, J.C. \& RODELLA, A.A. Avaliação química de corretivos de acidez para fins agrícolas: uma nova proposição. Sci. Agric., 53:211-216,1996.

ALVAREZ V., V.H. Avaliação da fertilidade do solo: superfícies de resposta - modelos aproximativos para expressar a relação fator-resposta. Viçosa, Universidade Federal de Viçosa, 1985. 75p.

BAHIA, V.G. Escória de siderurgia como corretivos da acidez do sol o. II. Trabalhos em casa de vegetação. Pesq. Agropec. Bras., 24:489-494,1989.

BELLINGIERI, P.A. Avaliação em laboratório da eficiência de diferentes frações granulométricas de calcários agrícolas. Piracicaba, Escola Superior de Agricultura "Luiz de Queiroz", 1983. 99p. (Tese de Doutorado)

BELLINGIERI, P.A.; ALCARDE, J.C. \& SOUZA, E.C.A. Avaliação da qualidade de calcários agrícolas através do PRNT. Na. ESALQ, 45:579-588,1988.

BRASI L. Ministério da Agricultura. Portaria no 3 de 12-06-1986 da Secretária de Fiscalização Agropecuária,1986.

BRASIL. Ministério da Agricultura. Secretaria Nacional de Defesa Agropecuária. Análise de corretivos, fertilizantes e inoculantes: métodos oficiais. Brasília: LANARV,1983.104p.

CAMARGO, A.P. Influência da granulometria de três materiais corretivos na neutralização da acidez do solo. Piracicaba, Escola Superior de Agricultura “Luiz de Queiroz", 1972. 59p. (Tese de Mestrado)

FORTES, J .L.O. Eficiência de duas escória de siderurgia, do Estado do Maranhão, na correção da acidez do solo. Viçosa, Universidade Federal de Viçosa, 1993. 66p. (Tese de Mestrado)

KATO, N. \& OWA, N. Dissolution of slag in water and calcium chloride solution: effects of solution $\mathrm{pH}$ and calcium concentration on solubilities of slags. J apan J . Soil Sci. Plant Nutr., 67:626-32, 1996. 
KURIHARA, C.H.; MAEDA, S.; HERNANI, L.C. \& SILVA, W.M. Eficiência relativa de frações granulométricas de cal cários Sul-Mato-Grossenses. Pesq. Agropec. Bras., 34:1443-1449, 1999.

LOUZADA, P.T.C. Eficiência de uma escória de siderurgia como corretivo de acidez do solo. Viçosa, Universidade Federal de Viçosa, 1987. 52p. (Tese de Mestrado)

NATALE, W. \& COUTINHO, E.L.M. Avaliação da eficiência agronômica de frações granulométricas de um calcário dolomitico. R.Bras.Ci. Solo, 18:55-62, 1994.

PIAU, W.C. Efeitos de escórias de siderurgia em atributos químicos de solos e na cultura do milho (Zea mays L.). Piracicaba, Centro de Energia Nuclear na Agricultura, 1995. 124p. (Tese de Doutorado)

PIAU, W.C. Viabilidade do uso das escórias como corretivo e fertilizante. Piracicaba, Centro de Energia Nuclear na Agricultura,1991. 99p. (Tese de Mestrado)

PLESE, L.P.M.; KIEHL, J.C.; PROCHNOW, L.I \& \& CORRENTE, J .E. Efeito da umidade do solo na reatividade das frações granulométricas de um calcário agrícola. In: REUNIÃO BRASI LEIRA DE FERTILIDADE DO SOLO E NUTRIÇÃO DE PLANTAS, 24., Santa Maria, 2000. Anais. Santa Maria, Sociedade Brasileira de Ciência do Solo, 2000. CD-ROM
POTAFOS. Disponível em: http://www.potafos.org. Acesso em 5 maio, 2003.

PRADO, R.M. \& FERNANDES, F.M. Escória de siderurgia e cal cário na correção da acidez do solo cultivado com canade-açúcar em vaso. Sci. Agric., 57:739-744, 2000.

PRADO, R.M.; FERNANDES, F.M. \& NATALE, W. Usoagrícola da escória de siderurgia como corretivo de acidez do solo: estudos na cultura da cana-de-açúcar. J aboticabal, Fundação de Estudos ePesquisas em Medicina Veterinária, Agronomia e Zootecnia, 2001. 67p.

RAIJ , B. van; CANTARELLA, H.; QUAGGIO, J .A. \& FURLANI, AM.C. Recomendação de adubação e cal agem para o estado de São Paulo. Campinas, Instituto Agronômico de Campinas, 1996. 285p. (Boletim, 100).

RAIJ , B.van.; ANDRADE, J .C.; CANTARELLA, H. \& QUAGGIO, J .A., eds. Análise química para avaliação da fertilidade do solo. Campinas, Instituto Agronômico de Campinas, 2001. 285p.

SWARTZENDRUBER, D. \& BARBER, S.A. Dissolution of limestone particles in soil. Soil Sci.100:287-291, 1965.

VIEIRA, S. Estatística experimental. 2.ed. São Paulo, Atlas, 1999. 185p. 